\title{
A Sightseeing Planning Support System with Gamification
}

\author{
Yuro Koga*, Kayoko Yamamoto \\ Graduate School of Informatics and Engineering, University of Electro-Communications, Tokyo, Japan \\ Email: *k2130040@edu.cc.uec.ac.jp
}

How to cite this paper: Koga, Y. and Yamamoto, K. (2021) A Sightseeing Planning Support System with Gamification. Journal of Geographic Information System, 13, 485-507.

https://doi.org/10.4236/jgis.2021.134027

Received: July 7, 2021

Accepted: August 2, 2021

Published: August 5, 2021

Copyright $\odot 2021$ by author(s) and Scientific Research Publishing Inc. This work is licensed under the Creative Commons Attribution International License (CC BY 4.0).

http://creativecommons.org/licenses/by/4.0/

(c) (i) Open Access

\begin{abstract}
In recent years, as there has been a major change in the necessity and importance of sightseeing information, a platform to provide real-time sightseeing information according to the ever-changing circumstances is necessary. Additionally, it is effective to adopt gamification to increase users' motivation to continuously utilize the system in order to provide them with more information. In the present study, in order to support users' enjoyment in creating efficient and pleasant sightseeing plans, the system that incorporates gamification to increase motivation was developed combining with web-geographic information systems (Web-GIS) and sightseeing planning and sharing system. The system was operated over a period of 2 weeks in Chofu City, Tokyo Metropolis, Japan. Based on the results of a questionnaire survey for 51 users, though the operability of the 3 main functions incorporated with motivation by gamification was rated lower than those of the 2 basic functions, their usefulness was highly rated. Based on the results of the access $\log$ analysis, it was effective to design the system so that the same functions can be used regardless of the type of information terminal. Additionally, it was evident that the continuous utilization of the system could increase the number of sightseeing plans created by the users.
\end{abstract}

\section{Keywords}

Sightseeing Planning Support System, Gamification, Mission, Sightseeing Plan Creation and Sharing System, Web Geographic Information Systems (Web-GISs)

\section{Introduction}

In the advanced information society of recent years, anyone can easily obtain necessary information, as there is an abundance of a wide variety of information on the internet. Additionally, with the spread of social networking services 
(SNS) in recent times, anyone can not only receive information but also send out information which in turn has accelerated the overflowing of information on the internet. The above can also be said about sightseeing information. In order to efficiently obtain sightseeing information, methods that use the internet are increasing in addition to the traditional way of using magazines and guidebooks. Blogs and review sites cannot be ignored as information sources besides SNS, and these are important methods to obtain sightseeing information. However, as there is a significant amount of information submitted on SNS, tourists must sort through information unrelated to tourism or their preferences by themselves, and that makes it difficult for them to obtain sightseeing spot information that suits their individual preferences. To solve such issues, a system that organizes the information provided according to each purpose is necessary.

Further, due to the impact given by the spread of COVID-19, there has been a major change in the necessity and importance of sightseeing information. Though information mainly associated with the appeal of sightseeing spots was valued in the past, the importance of information on infection control measures and congestion situations has also increased. Therefore, a platform to provide real-time sightseeing information according to the ever-changing circumstances is necessary.

Additionally, it is effective to adopt gamification to increase users' motivation to continuously utilize the system in order to provide them with more information. According to Basten [1] and Stieglitz et al. [2], games can help to motivate people in otherwise nongame scenarios and engage users in high interaction. According to Werbach et al. [3], good results may be easier to achieve by incorporating game elements and design technology into non-game contexts, as people are more likely to want to be involved, and experiments can be promoted without the fear of failure. Stieglitz et al. [2], Dreimane [4] and Kim et al. [5] pointed out that gamification was adopted especially into the academic fields related to education and learning. Additionally, Turan et al. [6], Van Roy et al., [7], Ozcinar et al. [8], Yamakawa et al. [9], Aoe et al. [10] showed the usefulness and significance of gamification utilized in school education. As introduced in Section 2, though recent studies developed sightseeing support systems incorporating gamification, there are not yet a lot of preceding studies that adopt gamification in sightseeing sector.

Based on the social and academic background shown above, the present study aims to design, develop, operate and evaluate a system that supports efficient and pleasant sightseeing planning while enjoying its process by adopting gamification to improve users' motivation. Specifically, a system that incorporates gamification to increase motivation combined with web-geographic information systems (Web-GIS) and sightseeing planning and sharing system is developed. Web-GIS enables the visualization of sightseeing spots on the digital map, while the sightseeing planning and sharing system enables users to share sightseeing information between other users that can be used in advance when planning sightseeing. 
In the present study, the original structure is comprised in accordance with the aim. Specifically, Section 2 introduces the major preceding studies of recent years in all parts of world in the related academic fields, and demonstrates the originality in the present study in comparison with the others. Sections 3 and 4 respectively designs and develops the unique system in the present study. Additionally, Sections 5 and 6 respectively operates and evaluates the developed system. Finally, Section 7 concludes the results of the present study and mentions the future research subjects.

\section{Related Work}

The present study is related to other three academic fields, namely: 1) studies related to the sightseeing planning support system; 2) studies related to the information sharing system between users; 3 ) studies related to the sightseeing system incorporating gamification. This present study is intended to introduce the major preceding studies of recent years in all parts of world in these three fields, and demonstrate its originality in comparison with others.

Regarding (1), Kurata et al. [11], Brilhante et al. [12] and Cenamor et al. [13] developed systems that interactively creates detailed sightseeing plans by suggesting sightseeing spots and routes according to their preferences. Yamamoto [14] and Abe et al. [15] developed sightseeing support systems using non-verbal information to provide users with necessary information and navigations. Ravi et al. [16] and Ikizawa-Naitou et al. [17] developed sightseeing support systems that integrated the route recommendation systems and referred transportation networks. Ravi et al. [18] and Chen et al. [19] proposed frameworks of the route recommendation systems using location based social networks (LBSNs).

Regarding (2), Yanagisawa et al. [20] and Nakahara et al. [21] developed information-sharing GIS that integrates Web-GIS, Wiki, and SNS to accumulate local knowledge in the local community. Okazaki et al. [22] and Usuda et al. [23] developed disaster information sharing systems for disaster response. Okuma et al. [24] and Murakoshi et al. [25] developed Social Media GIS to accumulate and utilize disaster information from normal times to disaster outbreak times. Platt et al. [26], Kochana et al. [27] and Chen et al. [28] proposed information sharing systems in healthcare sectors.

Regarding (3), as mentioned in Section 1, Ishikawa et al. [29], kawanaka et al. [30], Hidaka et al. [31] and Egger et al. [32] developed sightseeing support systems incorporating gamification. In addition to these studies, Mesáro et al. [33], Bujari et al. [34], Panou et al. [35] and Kotsopoulos et al. [36] targeted cultural, historical and natural heritages, and provided users with the information concerning these places and supported their excursion behaviors.

Regarding (1), a function that enables users to share sightseeing information generated in the system with other users has not been developed. Additionally, the above preceding studies only provide sightseeing spot information saved in the database, and cannot create sightseeing plans that include the visits to hid- 
den gems. In the study conducted by Kurata et al. [11], though a function to submit the plans created using various SNS has been developed, a function to view information of other users on the system is not implemented, and hence reviews by experienced tourists as prior information cannot be obtained. Regarding (2), a cold start is a possibility, as the supply amount of information is dependent on the number of system users. Regarding (3), while a system that adopts gamification to improve users' motivation has already been suggested and developed, a system that corresponds to the purpose of the present study has not been developed.

In comparison with the preceding studies mentioned above, the first originality in the present study is where the system integrates sightseeing planning and sharing system to Web-GIS, and that enables the visualization and sharing of sightseeing plans created by each user on the digital maps. The second originality is the promotion of the effective utilization of the system that supports sightseeing planning by users adopting gamification.

\section{System Design}

\subsection{System Features}

The system is made up of Web-GIS and sightseeing planning and sharing system. Figure 1 shows the features of each system. It is assumed that the system will be used on PCs and mobile information terminals. Since there is no difference in functions depending on the information terminal used, the same functions can be used from both PCs and m-bile information terminals.

When using the system for the first time, users will create an account for the system and register their information in the database. The purpose of the system is to accumulate sightseeing plans created by tourists so that users can obtain those information as prior information when making new sightseeing plans, and

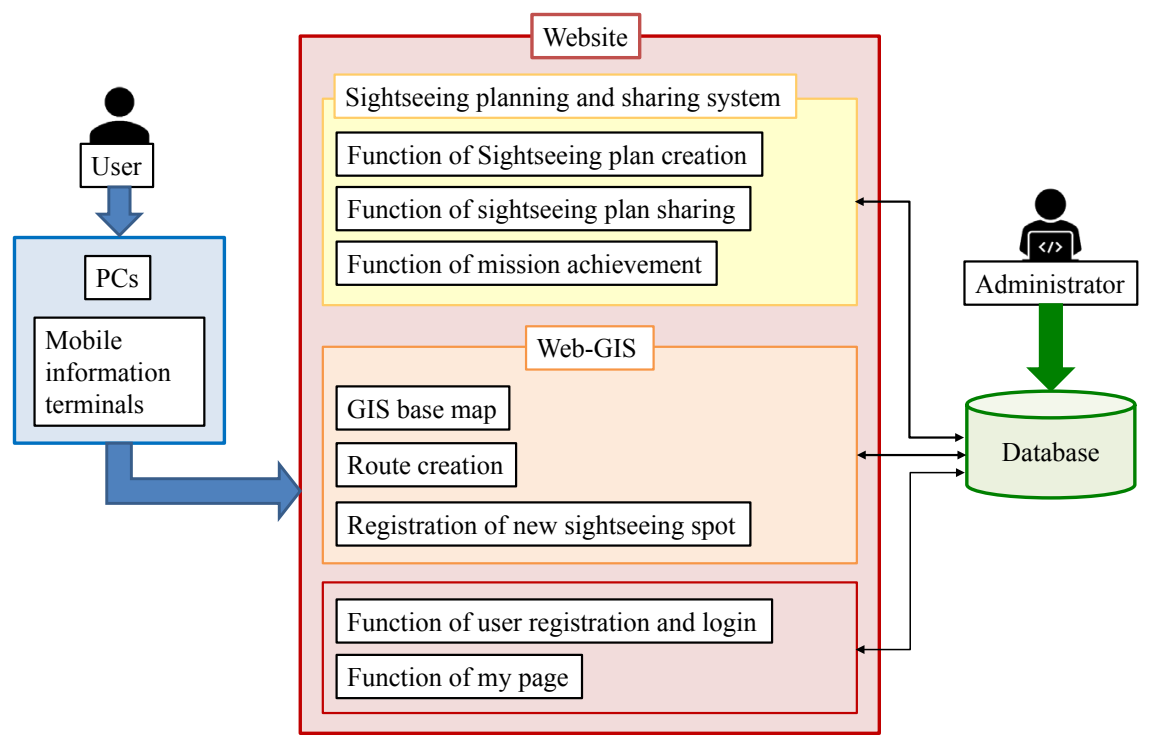

Figure 1. System design. 
the system is operated as a platform that can create and share sightseeing plans. Additionally, gamification is incorporated in the functions of sightseeing plan creation and sharing, and mission achievement as introduced later in Section 4.1. When registering new sightseeing spots, users can select those locations on the digital map of Web-GIS and submit its names, introductions and images. A sightseeing plan can be created by entering information concerning several sightseeing spots. Furthermore, the sightseeing plans that are individually created by users can be shared among all of them.

\subsection{System Usability}

1) Obtaining of prior sightseeing information

For people who are less informed concerning sightseeing spots or lack locality, gathering necessary information from the significant amount of various sightseeing information online can be difficult. Therefore, in order to efficiently support users, the function to share and provide them with sightseeing information and the function to purchase and save sightseeing plans created by others using virtual money can be used. With the function to share created sightseeing plans, prior information can be more easily obtained, as popular sightseeing plans are made visible to many users.

2) Obtaining of real-time information

Users can obtain the latest information, as the registration date are added to the names, introductions and images of the sightseeing spots.

3) Grasp of the locations sightseeing spots

Users can easily grasp the location of each sightseeing spot, as they are displayed on the digital map of Web-GIS. Additionally, when several sightseeing spots are selected, the positional relationship between each spot can be grasped on the digital maps, and that enables users especially who lack a sense of locality to imagine the distance and route in detail.

4) Continuous utilization of the system

Gamification is incorporated, as it is necessary to promote the continuous utilization of the system to provide users with more information.

\subsection{System Operation Environment}

The system is operated using the Web server, database server and the GIS server. The system operating environment is as shown in Figure 2. Heroku, which is a PaaS provided by the Salesforce company, was used for both the Web server and the database server. ArcGIS Online, which is provided by the Environmental Systems Research Institute, Inc. (ESRI), was used for the GIS server. Additionally, the web application developed with the system was implemented using PHP, JavaScript and HTML.

\subsection{Design of Each System}

\subsubsection{Sightseeing Planning and Sharing System}

In sightseeing planning and sharing system, sightseeing plans are created and 


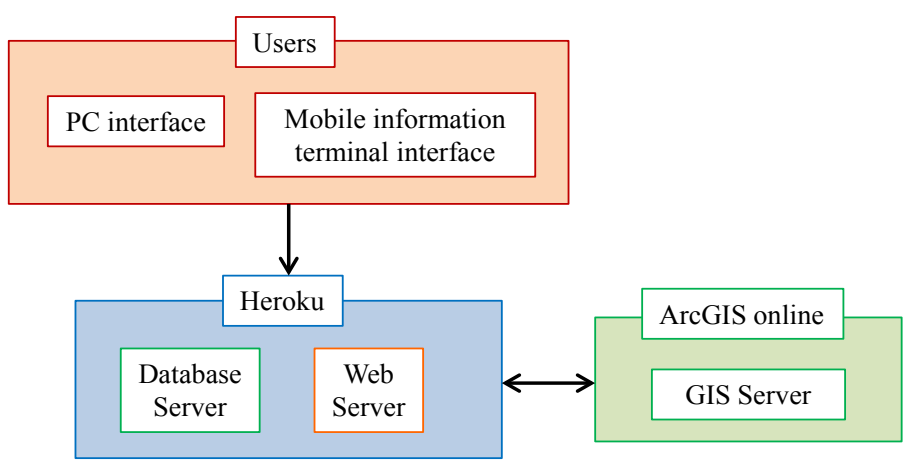

Figure 2. System operating environment.

submitted in order to share the information as prior information before sightseeing, and those plans created by other users are viewed and evaluated. Additionally, sightseeing plans are created and shared adopting gamification to effectively promote users' involvement in the system. The design details are shown below.

1) Sightseeing plan creation system

Users who are experienced tourists can register their sightseeing records as past in-formation so that users with no experience can use this as a reference to create sightseeing plans. By selecting a sightseeing spot displayed on the digital map of Web-GIS, its name, introduction, image and creation date can be registered. Additionally, the title and introduction for the entire sightseeing plan can also be registered. The registered contents will be saved in a CSV file within the database server.

2) Sightseeing plan sharing system

Plans created by other users can be viewed as prior information when creating sightseeing plans. The contents of each sightseeing plan saved to the database are listed in the order of the date they were created. This list contains the title, introduction, user ID of the creator, creation date as well as the "Details" button of the sightseeing plan. When users press the "Details" button, information of the sightseeing plan is displayed on the digital map of Web-GIS along with its location information, and the registered information of each sightseeing spot can be viewed.

3) Gamification-related system

Various motivations of gamification are adopted to promote the voluntary participation of users in the system. Kurata [37] summarized the motivations by gamification into the following 9 items: "provision of a worldview and story", "onboarding", "score and ranking visualization", "presenting of a mission and goal", "badge and level", "competition", "social", "speedrun elements" and "comeback elements". Table 1 shows the relevance between functions and motivations by gamification incorporated in the system.

\subsubsection{Web-GIS}

There are various types of Web-GIS, and the appropriate type must be selected 
Table 1. Relevance between functions and motivations by gamification incorporated in the system.

\begin{tabular}{ll}
\hline Functions & Motivations by gamification \\
\hline & $\begin{array}{l}\text { Users can increase their virtual money when others purchase their } \\
\text { sightseeing plans that they created. This increases the users' motivation } \\
\text { to create plans and at the same time promotes their active involvement in } \\
\text { the system. }\end{array}$ \\
Score visualization & $\begin{array}{l}\text { Users are induced to create sightseeing plans through missions prepared } \\
\text { related to the sightseeing planning. }\end{array}$ \\
Mission presentation & $\begin{array}{l}\text { Users can evaluate sightseeing plans created by other users with the } \\
\text { "like" button that is implemented on the sightseeing planning and } \\
\text { sharing system. }\end{array}$ \\
\hline
\end{tabular}

according to the purpose of use. As the system is expected to be used by a wide range of age groups, a system that can be used by simply connecting to the internet via a browser without having to install specific software is desirable for convenience. In the present study, a Web-GIS is developed adopting ArcGIS for JavaScript provided by the ESRI. Design details are shown below.

1) Display of sightseeing spots saved to the database

By displaying sightseeing spot information on the digital map of Web-GIS, users can easily grasp the location of each sightseeing spot. Additionally, by displaying sightseeing spots by color according to their category, it is easy to confirm the categories and locations of sightseeing spots, when looking down at the digital map.

2) Display of sightseeing plan routes

When creating a sightseeing plan, users can visually confirm their sightseeing route, as the directions of the sightseeing spots in the order they were selected are displayed by a line on the digital map of Web-GIS. Therefore, users who may lack a sense of locality can also imagine the distance and route in detail.

\section{System Development}

\subsection{The Frontend of the System}

In the present study, the original functions for users as described in detail below are implemented. The frontend of the system is made up of 2 basic functions (function of user registration and login, and function of my page) and 3 main functions (function of sightseeing plan creation, function of sightseeing plan sharing, and function of mission achievement).

\subsubsection{Function of User Registration and Login}

In order to utilize the system, users will transit from the page for the function of login to the page for the function of user registration to register with the system. On this page, users will register their IDs and passwords as their information. Once the information is submitted, users will log in with the registered information and go to the page for the function of sightseeing plan sharing page. Figure 3 shows the process of user registration and login. 


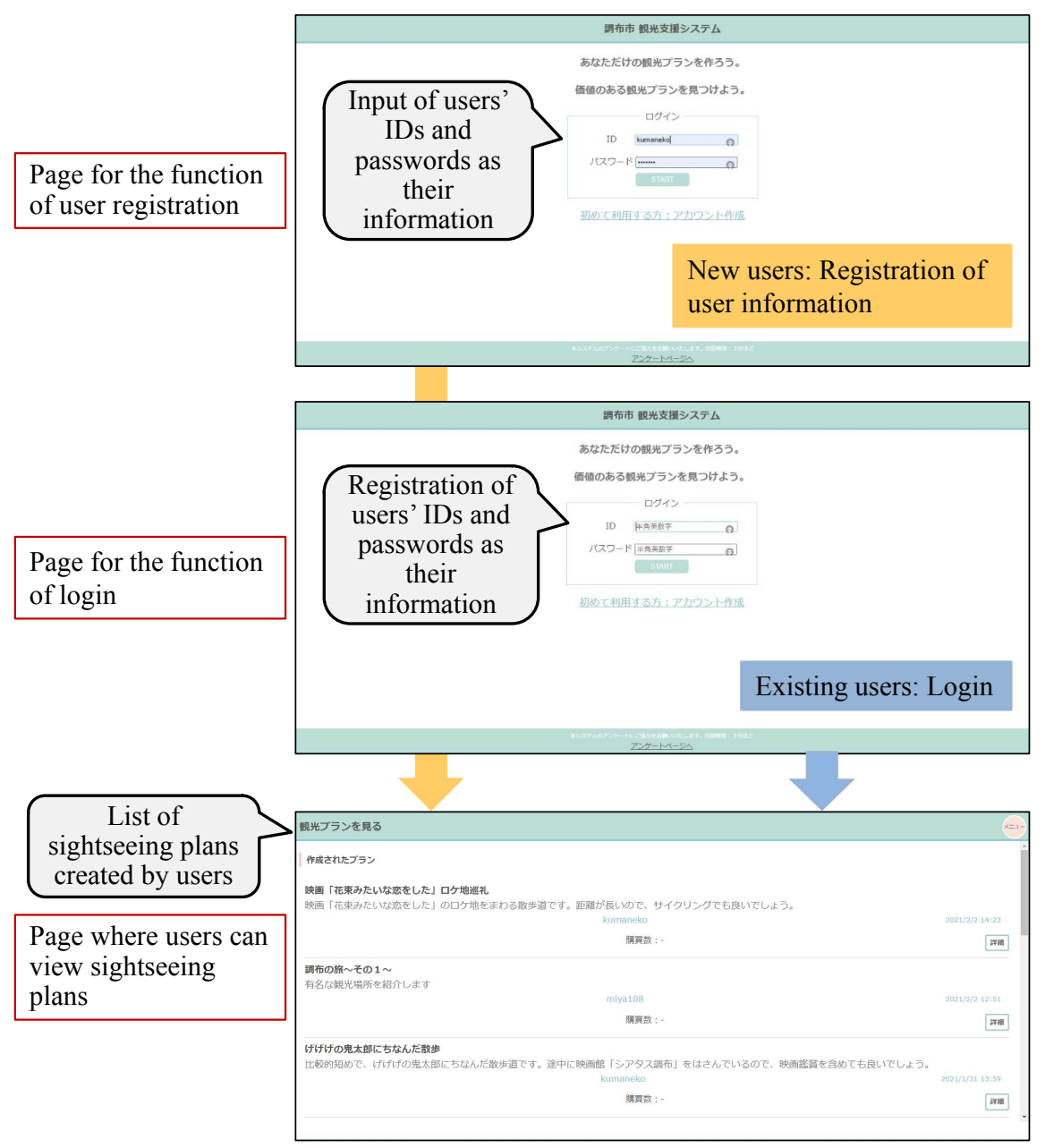

Figure 3. Process of user registration and login.

\subsubsection{Function of Sightseeing Plan Creation}

After logging into the system, users can click on the menu button at the upper-right corner of the page to pull down the menu, and select "Create a sightseeing plan" to create a sightseeing plan. By clicking on the round icon on the digital map of Web-GIS, a popup with information concerning a sightseeing spot will be displayed. Sightseeing plans can be created by registering the information displayed in the popups. Once the selecting of sightseeing spots is completed and the "Spot selection complete" button is pressed, users will transit to a page where they can enter the title and introduction of their sightseeing plan. After entering the necessary information and clicking on the "Plan complete" button, the sightseeing plan is completed. Figure 4 shows the process of sightseeing plan creation after pressing the "Spot selection complete" button.

In this function, a subfunction to register new sightseeing spots is also implemented. Figure 5 shows the page for the subfunction of sightseeing spot registration. A list of sightseeing spots which is saved to the database is displayed in the page for the function of sightseeing plan creation, and users can utilize this function to add new sightseeing spots and save them to the database. When 


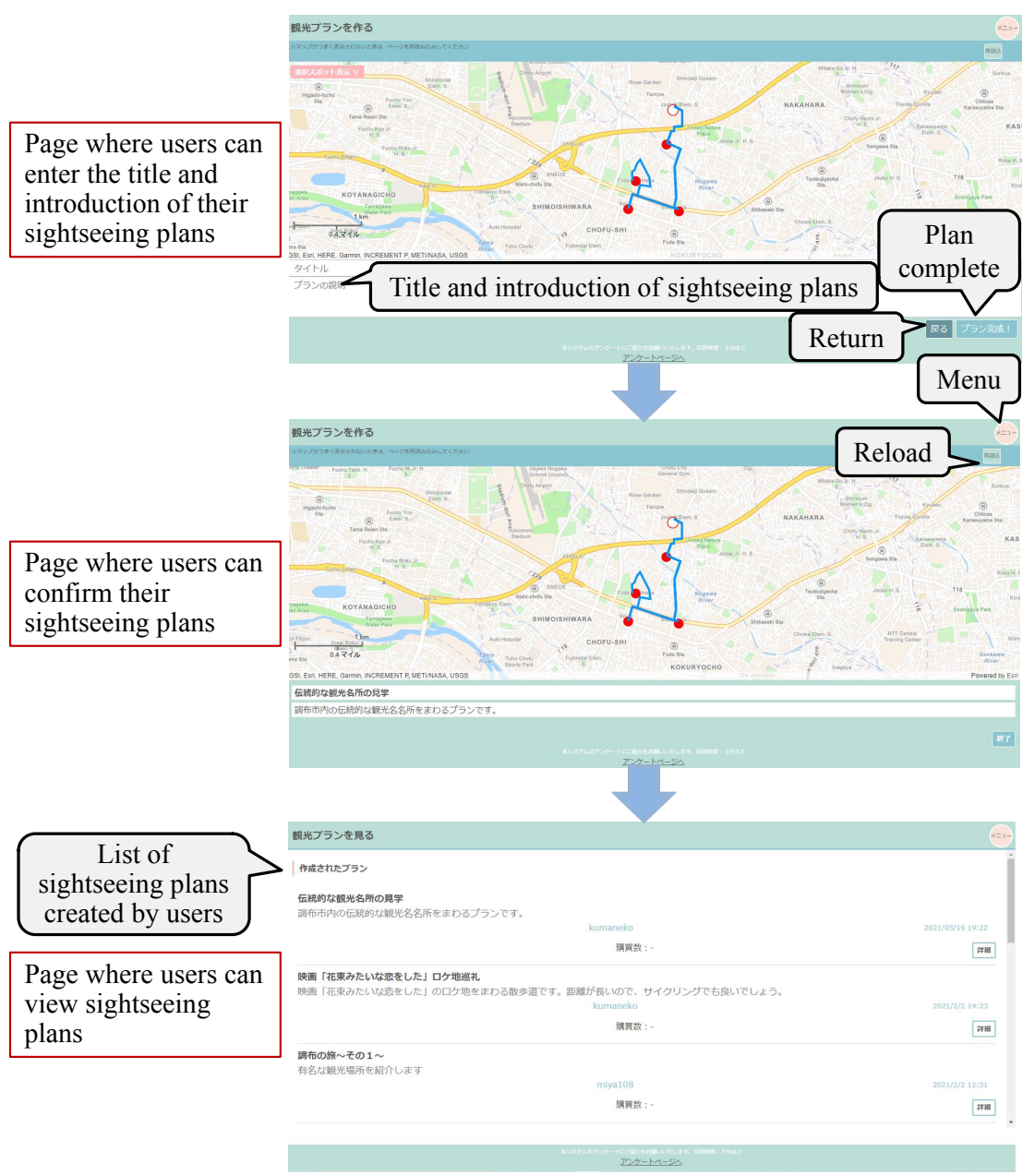

Figure 4. Process of sightseeing plan creation.

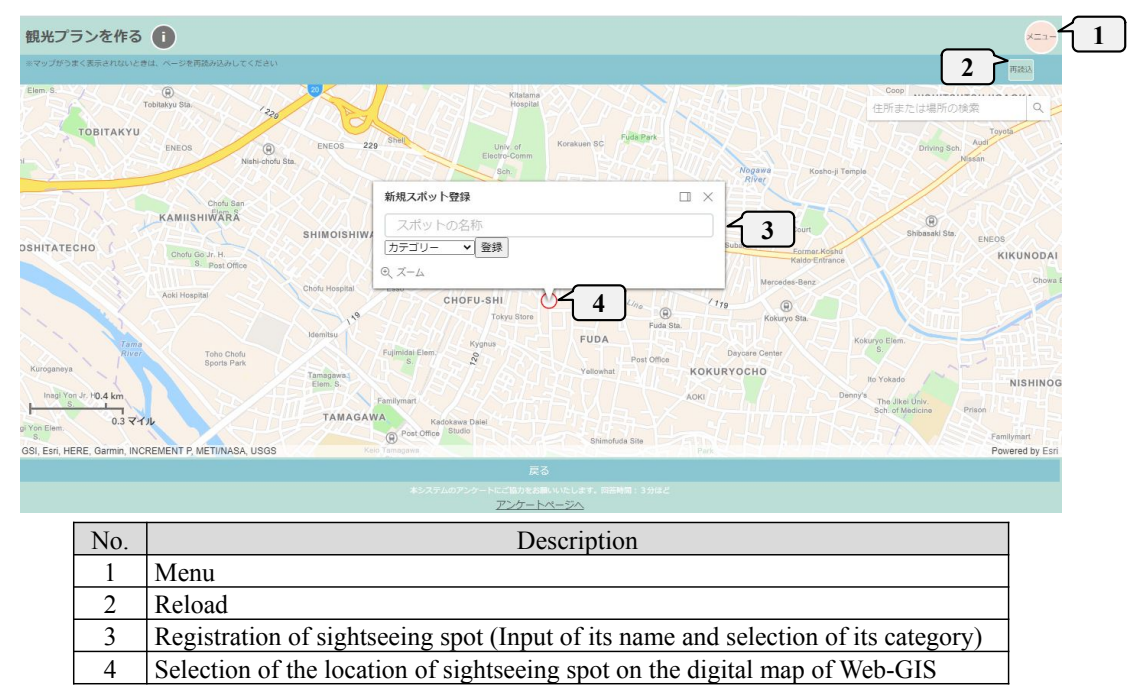

Figure 5. Page for the subfunction of sightseeing spot registration.

clicking on the "+" button on the right side of the page, users will transit to the page for the subfunction of sightseeing spot registration. On this page, the 
"name of sightseeing spot" can be entered and a "category" can be selected. The category can be selected from "famous and historical site", "park and botanical garden", "public facility", "eating and drinking establishment", "temple and shrine", "art museum and museum", "hot spring (onsen)", "flower-viewing (hanami)", "festival and event", "theme park", and "others".

\subsubsection{Function of Sightseeing Plan Sharing}

Figure 6 shows the page for the function of sightseeing plan sharing. Users will transit to this page by selecting the "View sightseeing plans" in the menu. On this page, the "Title", "Introduction", "User ID", "Creation date", and "Number of the users who purchase sightseeing plan" are displayed. By clicking on the "Details" button and either the "Title" and "Introduction", users will transit to the page where details of a sightseeing plan can be viewed. Figure 7 shows the page of the details of a sightseeing plan.

On the page for the details of sightseeing plan, users can view the sightseeing plan on the digital map of Web-GIS. Users can give a sightseeing plan a high rating by clicking on the heart icon ("like" button) at the lower left of the page. Users can also save favorite sightseeing plans to their "My Page" using their virtual money by clicking on the "Purchases" button at the lower right of this page. The currency unit used in the system is "Kitaro" that is the name of the main character in Japanese famous cartoon. When a user purchases a sightseeing plan, the buyer spends 100 Kitaro while the creator gains 100 Kitaro. Figure 8 shows the process of purchasing a sightseeing plan.

\subsubsection{Function of Mission Achievement}

Figure 9 shows the page for the function of mission achievement. Users will transit to this page by selecting the "Mission" from the menu. On this page, the mission items and their progress are displayed as a list. When a mission is achieved,

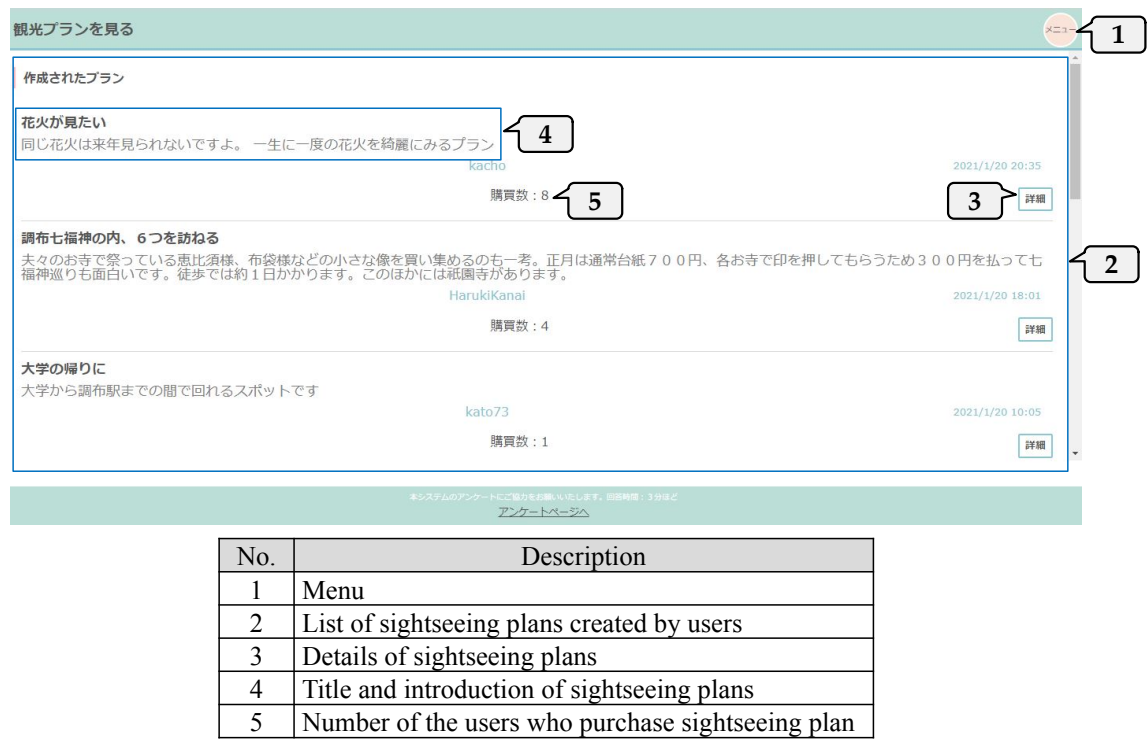

Figure 6. Page for the function of sightseeing plan sharing. 


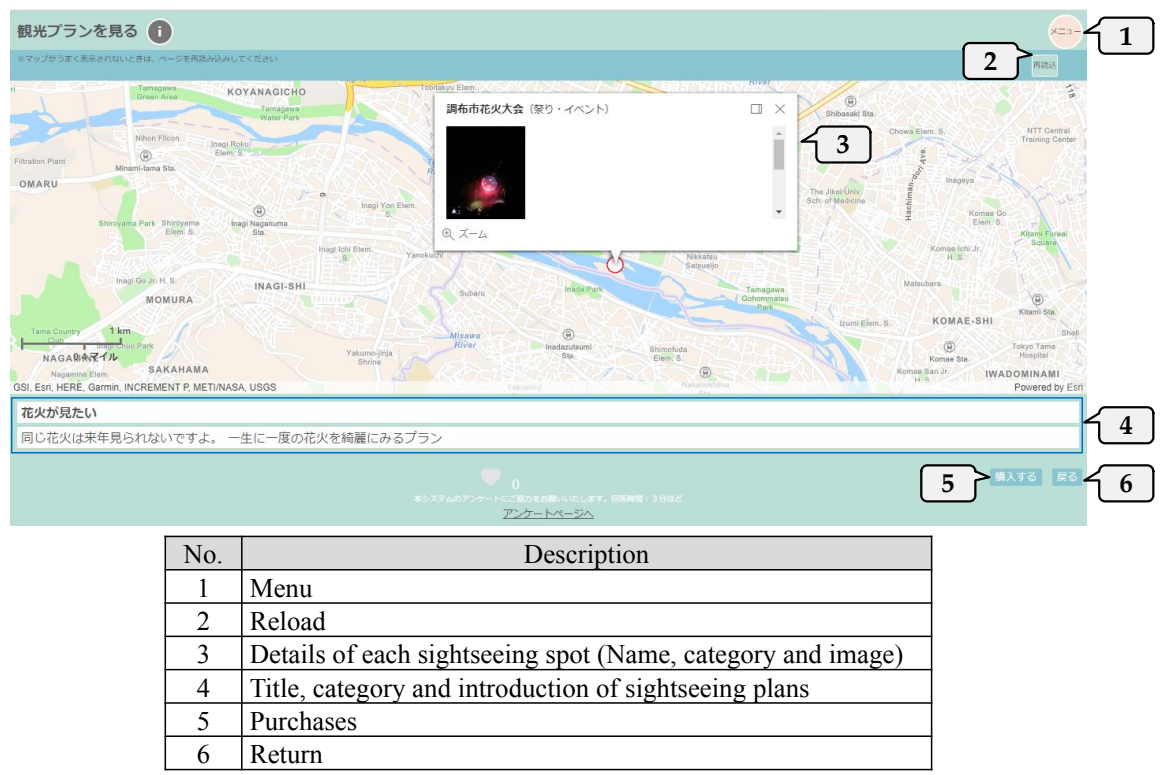

Figure 7. Page for the details of a sightseeing plan.

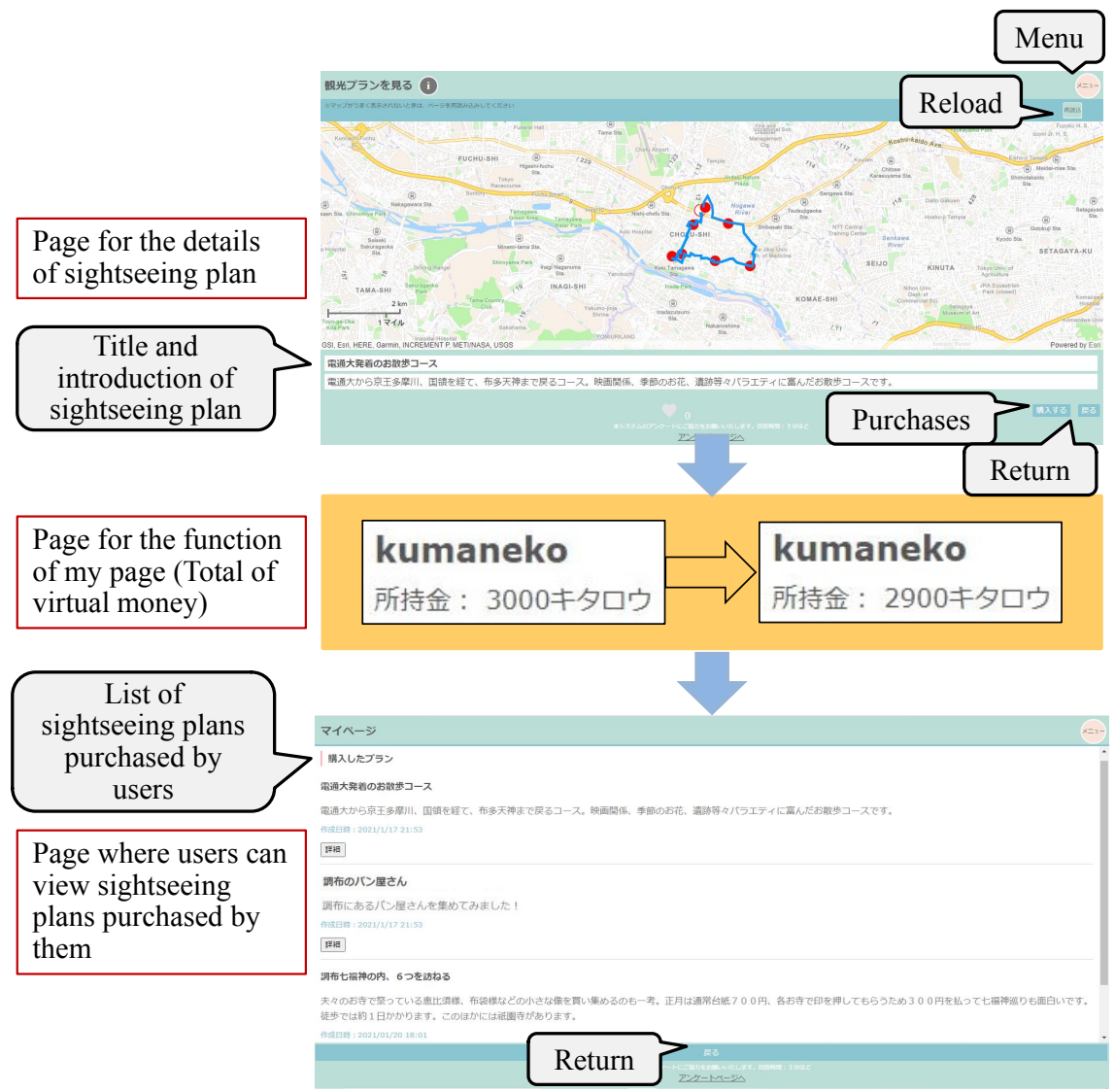

Figure 8. Process of purchasing sightseeing plan.

the item that was shown as "Unachieved" will change to "Achieved" and the "Reward" button will appear. By clicking on the "Reward" button, users can increase their virtual money. 

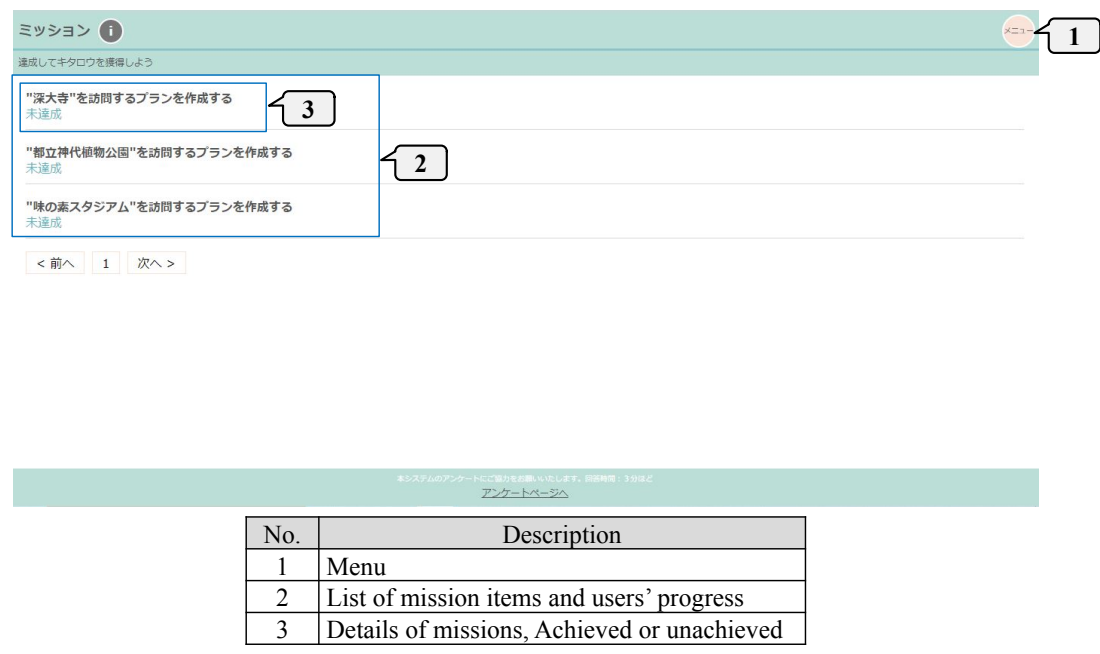

Figure 9. Page for the function of mission achievement.

\subsubsection{Function of My Page}

Figure 10 shows the page of the function of my page. Users will transit to this page by clicking on "My Page" in the menu or their User IDs. On this page, users can view their User IDs, accumulated virtual money, purchased sightseeing plans, and the history of sightseeing plans created by themselves.

\subsection{The Backend of the System}

\subsubsection{Process of the Registration of User Information and Login}

The registered user information is saved in a CSV file in the Heroku database. At this point, the password is hashed using a hash function of PHP and saved to the database. When logging in, the password is hashed in the same way to confirm that the ID and password in the database match, before the login process is conducted. If they do not match, an error message is displayed and users must enter their information again.

\subsubsection{Process of the Function of Sightseeing Plan Creating}

The process of adding and saving the information entered in the function of sight-seeing plan creating to the $2 \mathrm{CSV}$ files is conducted at the backend. Regarding the $2 \mathrm{CSV}$ files, one is used to save the titles and introductions of sightseeing plans and the central coordinates and enlargement ratio on the digital maps of Web-GIS, and the other is used to save the name, category, introduction and image of each sightseeing spot within sight-seeing plans.

\subsubsection{Process of the Function of Sightseeing Plan Sharing}

For the viewing of sightseeing plans in the function of sightseeing plan sharing, the process of outputting the sightseeing plans saved in the database to the page of this function, and the process of rating using the "like" button are performed. Additionally, in terms of purchasing sightseeing plans, the process of updating the number of purchased sightseeing plans and saving the purchased sightseeing plan as well as the process of de-creasing the virtual money of the buyer and increasing the creator's virtual money are performed. 


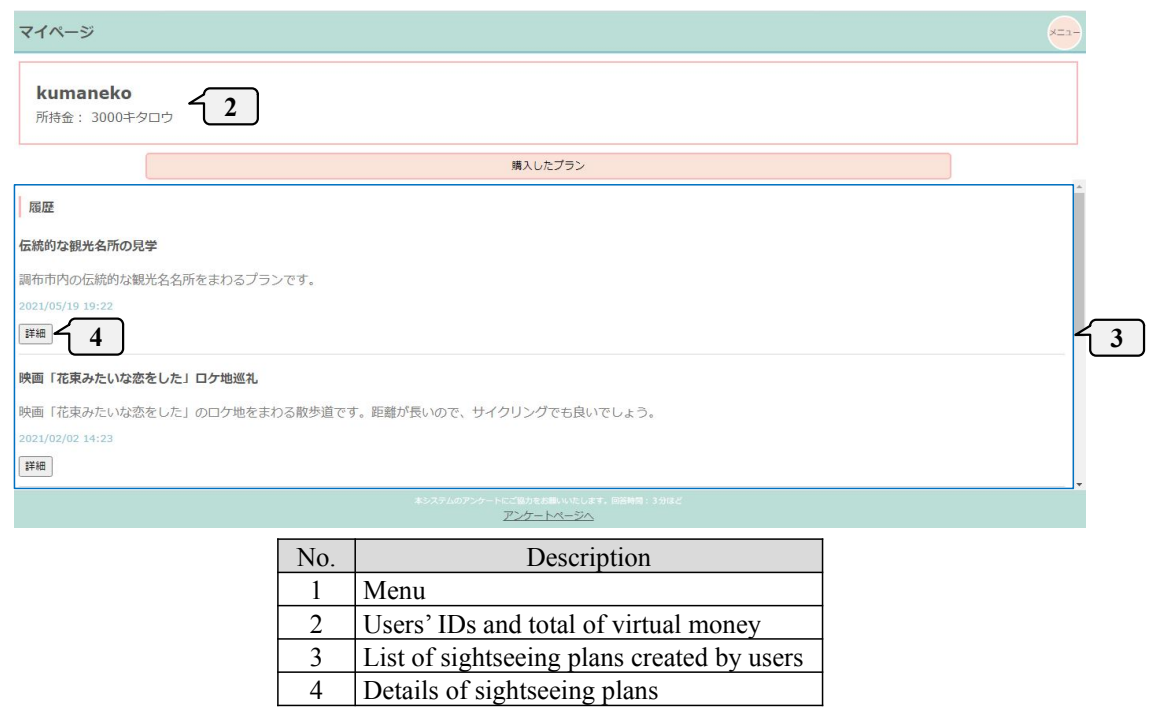

Figure 10. Page for the function of my page.

\subsubsection{Process of the Function of Mission Achievement}

In the function of mission achievement, the process of checking the mission list in the database and determining whether the mission has been achieved or not, the process of updating the mission list if a mission has been achieved, and the process of increasing the virtual money as a reward for completing a mission are performed.

\subsection{System Interface}

The interface of the system has two types: the screens of PCs and mobile information terminals for users, and the screen of PCs for administrator. Regarding the screens for users, a responsive design was selected and two types of interfaces were prepared according to the screen size of the information terminals used. The interface for mobile information terminals is mostly the same as the interface for PCs. On the screens for administrator, users, sightseeing spot information, and submitted information can be managed.

\section{Operation}

\subsection{Selection of the Operation Target Area}

The area around Chofu City, Tokyo Metropolis was selected as the target area for the system operation. The reason for this is that there are various sightseeing spots scattered about in different places throughout the city, and many sightseeing spots can be visited on foot as the whole city is mostly flat.

The system was assumed to be utilized by both people who are familiar with the operation target area and can create sightseeing plans, and people who are not so familiar with the area but desire to sightsee and share as well as purchase sightseeing plans created by other users. The former will create sightseeing records using the function of sightseeing plan creating, and gather new sightseeing information using the function of sightseeing plan sharing. On the other hand, the 
latter will use the function of sightseeing plan sharing to share and purchase sightseeing plans from other experienced travelers which can reduce the burden of creating sightseeing plans.

\subsection{Data Gathering of Sightseeing Spots}

In order to utilize the system functions immediately after the start of the operation, the data concerning sightseeing spots must be gathered beforehand. Regarding the data concerning sightseeing spots for the system, information of a total of 87 sightseeing spots within Chofu City that were listed and evaluated in the tourism category of the travel review site of 4travel.jp [38], was gathered.

\subsection{Operation Results}

The system operation was conducted for a period of 2 weeks with people inside and outside the operation target area as subjects. The authors promoted the utilization of the system through the website, Twitter, Instagram and Facebook of their lab.

Table 2 shows the system users. There were a total of 51 users with many in their 20 s. $49 \%$ were in their 20 s, $18 \%$ were in their 30 s, $16 \%$ were in their 60 s and over, $10 \%$ were in their 40 s, $7 \%$ were in their 50 s. This shows that the system was utilized by a wide range of age groups. Additionally, only $27 \%$ lived in Chofu City, while $41 \%$ lived in Tokyo Metropolis, and 32\% lived in the Tokyo Metropolitan Area. Therefore, it can be said that over $70 \%$ of system users had no sense of locality concerning Chofu City and were not familiar with the sightseeing spots.

There were 17 sightseeing plans created during the operation period. Figure 4 and Figure 8 show examples of the sightseeing plans created by users. Additionally, there were 30 new sightseeing spots registered during the operation period. Table 3 shows the breakdown of registered sightseeing spots according to category. Table 3 suggests that the creation of new sightseeing plans and the registration of new sightseeing spots by users can be anticipated by operating the system for an extended period.

\section{Evaluation}

After the end of the operation, a questionnaire survey for users and an access log analysis were conducted to evaluate the system.

\subsection{Evaluation Based on the Questionnaire Survey}

\subsubsection{Overview of the Questionnaire Survey}

According to the purpose of the present study, a questionnaire survey was conducted to 1) evaluate the system utilization, 2) evaluate the operability of each function, and 3) evaluate the usefulness of the main functions and the overall system. The survey was conducted on the website 1 week after the start of the operation. Table 2 also shows the overview of the questionnaire survey. As indicated in Table 2, all 51 users responded making the valid response rate $100 \%$. 
Table 2. Breakdown of system users and questionnaire survey respondents.

\begin{tabular}{cccccccc}
\hline Age groups of users & $10-19$ & $20-29$ & $30-39$ & $40-49$ & $50-59$ & $60+$ & Total \\
\hline Number of users (people) & 0 & 25 & 9 & 5 & 4 & 8 & 51 \\
\hline
\end{tabular}

Table 3. Breakdown of the number of registered sightseeing spots according to category.

\begin{tabular}{ll}
\hline \multicolumn{1}{c}{ Category } & Number of registered sightseeing spots \\
\hline Famous and historical site & 1 \\
Park and botanical garden & 6 \\
Public facility & 4 \\
Eating and drinking establishment & 11 \\
Temple and shrine & 2 \\
Art museum and museum & 1 \\
Hot spring (Onsen) & 0 \\
Flower viewing (Hanami) & 1 \\
Festival and event & 0 \\
Theme park & 0 \\
Others & 4 \\
Total & 30 \\
\hline
\end{tabular}

\subsubsection{Evaluation of the System Utilization}

All users of the system use the internet every day. Additionally, regarding the methods to obtain sightseeing information (multiple answers allowed), 92\% were smartphones, $80 \%$ were PCs, and $43 \%$ were guidebooks. Social media was not used as much, as the use of Twitter, Instagram and Facebook were 17\%, 12\% and $12 \%$ respectively. $4 \%$ of users used review sites. From this, while information was gathered using printed media such as guidebooks as well as review sites, many users gathered sightseeing information using the internet from their PCs and smartphones. Additionally, it cannot be ignored that various kinds of social media were used as methods to gather sightseeing information. From the above, it was evident that the system is effective in supporting sightseeing, as sight-seeing information can be gathered online using PCs and mobile information terminals.

\subsubsection{Evaluation of the Operability of Each Function}

Figure 11 shows the evaluation results of the operability of each function. Regarding the operability of the function of user registration and login as the most basic function of the system, $84 \%$ responded with "I think so" or "I somewhat think so" which indicates that this function was easy to operate.

Regarding the operability of the function of sightseeing plan creating, while $51 \%$ responded with "I think so" or "I somewhat think so", 27\% responded with "I don't think so" or "I don't think so at all". Accordingly, this function has a higher percentage of negative feedback comparing to other functions. The reason 
Function of user registration and login

Function of sightseeing plan creating

Subfunction of sightseeing spot registration

Function of sightseeing plan sharing

Function of mission achievement

Function of my page

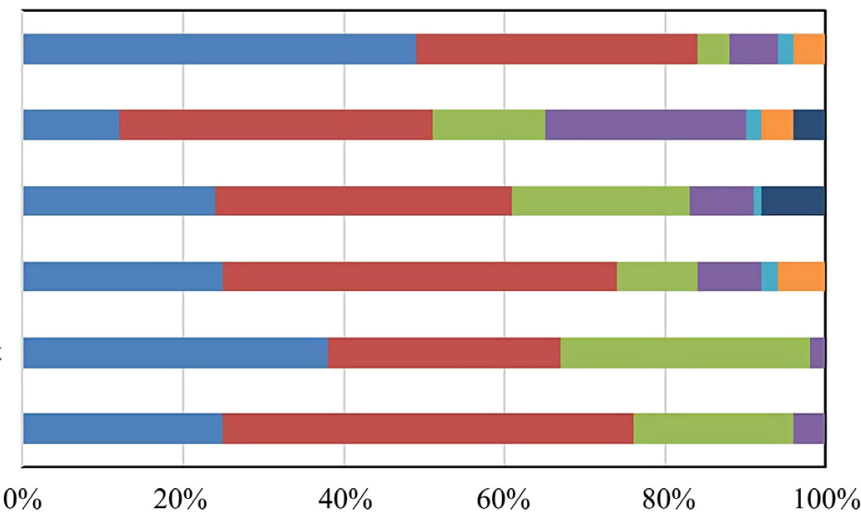

\begin{tabular}{|l|l}
\hline I think so & $\square$ I somewhat think so $\square$ Neither \\
$\square$ I don't think so at all $\square$ Others & $\square$ I didn't use it
\end{tabular}

Figure 11. Evaluation results of the operability of each function.

for this is that it took a bit of a while for some users to display digital maps and the size of the popups on the digital map was small. Therefore, it can be said that the digital map of Web-GIS should be further examined. As introduced in Section 4.1.2, the subfunction of sightseeing spot registration is implemented in the function of sightseeing plan creation. Regarding the operability of this subfunction, $61 \%$ responded with "I think so" or "I somewhat think so", while $9 \%$ responded with "I don't think so" or "I don't think so at all”. Additionally, $8 \%$ responded with "I didn't use it", because some users may lack a sense of locality in the operation target area.

Regarding the operability of the function of sightseeing plan sharing, $74 \%$ responded with "I think so" or "I somewhat think so". Several users who responded with "Others" commented that "it would be better if the travel time, distance and method of each sight-seeing plan are listed". This suggested that there is room to examine the information input when creating sightseeing plans.

Regarding the operability of the function of mission achievement, $67 \%$ responded with "I think so" or "I somewhat think so", while $31 \%$ responded with "Neither". The reasons for this are that the feedback when achieving missions was not sufficient and the methods to achieve each item were difficult to understand. However, this function can be improved by changing the design and providing users with a detailed introduction of how to achieve the mission items.

Regarding the operability of the function of my page as the basic function of the sys-tem, 76\% responded with "I think so" or "I somewhat think so", while $20 \%$ responded with "Neither". As the reason for this it that the history of sightseeing plans created by users was difficult to view, it is necessary to improve the design of this function.

\subsubsection{Evaluation of the Usefulness of the Main Functions and the Overall System}

Figure 12 shows the evaluation results of the usefulness of the 3 main functions 
Function of sightseeing plan creating

Function of sightseeing plan sharing

Function of mission

achievement

Overall system

Wish to continue utilizing the system

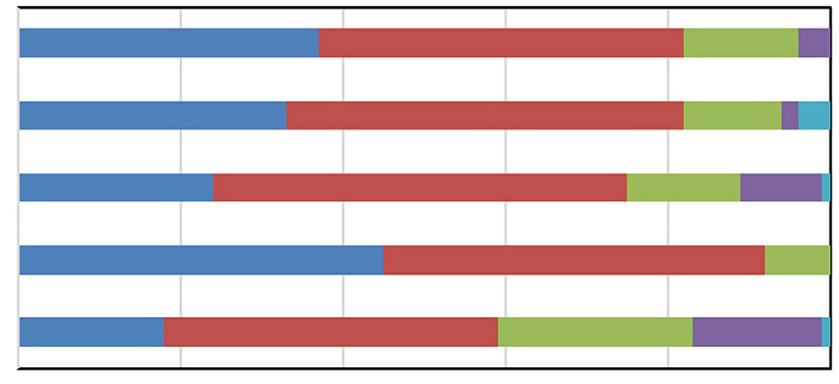

\begin{tabular}{llllll}
\hline & $20 \%$ & $40 \%$ & $60 \%$ & $80 \%$ & $100 \%$
\end{tabular}

$\square$ I think so $\square$ I somewhat think so $\quad$ Neither $\quad$ I don't think so $\square$ I don't think so at all

Figure 12. Evaluation results of the usefulness of the main functions and the overall system.

and the overall system. As clearly shown in Figure 12, though the 3 main functions were highly evaluated by users, the rate of high evaluation related to the function of mission achievement was slightly lower than those related to other 2 functions.

Regarding the usefulness of the function of sightseeing plan creating, $83 \%$ responded with "I think so" or "I somewhat think so". Therefore, this function was useful in recording the sightseeing activities of users and generating past information. Regarding the usefulness of the function of sightseeing plan sharing, $82 \%$ responded with "I think so" or "I somewhat think so". Therefore, it can be said that the sharing of sightseeing plans created by other users contributes to sightseeing support. Regarding the usefulness of the function of mission achievement, $76 \%$ responded with "I think so" or "I somewhat think so". Therefore, it is effective in increasing the users' motivation for sightseeing. As evident in Figure 11 , the operability of these main functions was not as high as the basic functions but was highly evaluated for their usefulness. Therefore, it can be anticipated that users can familiarize themselves with the operation of the main functions by the continuous utilization of the system, and that will enable them to easily use those functions.

Regarding the usefulness of the overall system, 92\% responded with "I think so" or "I somewhat think so" indicating that the system is useful in supporting sightseeing. Regarding the wish to continue utilizing the system, 59\% responded with "I think so" or "I somewhat think so", while $24 \%$ responded with "Neither" and $17 \%$ responded with "I don't think so". The reason for this may be that only $27 \%$ of the system users lived within Chofu City.

\subsection{Evaluation Based on the Access Analysis}

An access analysis was conducted in the present study using the log data of users during the operation period. The present study used the Google Analytics of Google. The access log can be obtained by invoking the PHP program, which is described with analysis code created by Google Analytics, from the HTML file loaded on each page within the website that is subject to access analysis. 
The total number of sessions in the system was 116 . For the information terminals used to access the system, 35\% used PCs, $60 \%$ used smartphones and 5\% used tablets. The reason for this is that smartphones are commonly used as a convenient method to obtain necessary information in recent years. Additionally, though small in number, there were a few users who accessed the system from tablet PCs. Therefore, it was effective to design the system so that it could be used in the same way regardless of the type of information terminal as mentioned in Sections 3.1 and 4.3.

Table 4 shows the top 9 visited pages. Based on Table 4, it is evident that the "Page for the function of sightseeing plan creation" and the "Page for the function of sightseeing plan sharing" have the most visits in the system. Therefore, the utilization of the system was in harmony with the purpose of the present study which was to have users create their own sightseeing plans and share them with other users. However, as the number of visits to the "Page for sightseeing plan complete" was low comparing to other pages, users transited to the "Page for the function of sightseeing plan creation", and only a few of them could complete creating those plans. These issues may be solved by having users become familiar with the function of sightseeing plan creating through the continuous utilization of the system.

\subsection{Identification of Improvement Plans}

The issues of the system identified based on the results of the questionnaire survey and access log analysis are summarized below.

1) Web page designs

It is desirable to implement a subfunction to change the font, color and size of character by users. This can improve the readability and visibility of texts, users in a wide range of age groups will be able to easily utilize the system. Additionally, regarding the page for the function of sightseeing plan creating, it is hopeful

Table 4. Number of visits per page (Top 9).

\begin{tabular}{|c|c|c|c|}
\hline Rank & Page name & $\begin{array}{l}\text { Number of } \\
\text { visits by page }\end{array}$ & Percentage (\%) \\
\hline 1 & Page for the function of sightseeing plan creation & 710 & 35.1 \\
\hline 2 & Page for the function of sightseeing plan sharing & 431 & 24.2 \\
\hline 3 & Login page & 283 & 14.0 \\
\hline 4 & Page for the subfunction of sightseeing spot registration & 188 & 9.3 \\
\hline 5 & $\begin{array}{l}\text { Page for the function of my page (A list of purchased } \\
\text { sightseeing plans) }\end{array}$ & 115 & 5.7 \\
\hline 6 & Page for the function of mission achievement & 90 & 3.4 \\
\hline 7 & Page for the function of my page & 88 & 3.3 \\
\hline 8 & Page for the function of user registration and login & 82 & 3.3 \\
\hline 9 & Page for the details of sightseeing plan & 37 & 1.7 \\
\hline
\end{tabular}


to display the popup when entering each information on the entire page. This can also improve the readability and visibility of texts, and raise the operability of users. Regarding the page for the function of sightseeing plan sharing, it is also hopeful to display the image of each sightseeing spot, and that will enable users to easily picture the sightseeing plans.

2) Function of sightseeing plan creating and sharing

Regarding this function, it is desirable to increase entry items, and implement a sub-function to automatically obtain users' actual sightseeing routes by means of global positioning system (GPS) installed into their mobile information terminals. These will save users the trouble when creating sightseeing plans, and they can efficiently create sightseeing plans and enhance sightseeing information based on their actual experiences.

3) Effective introduction of increasing motivation by gamification

As mentioned in Section 3.4.1, 3 motivations by gamification were adopted. These are incorporated in the 3 main functions which should be modified for the improvement in operability. Additionally, by incorporating motivations by gamification including the "provision of a worldview and story" and "onboarding" introduced in Section 3.4.1, more high-quality sightseeing plan can be gathered and accumulated, and that will enable the system to effectively support the sightseeing of users. The continuous utilization of the system can be promoted to users by effectively adopting motivations by gamification.

\section{Conclusions}

The present study consisted of the design and development of the system (Sections 3 and 4), followed by its operation (Section 5), evaluation and identification of improvement plans (Section 6), which can be summarized into the following 3 points.

1) In the present study, in order to support users' enjoyment in creating efficient and pleasant sightseeing plans, the system that incorporates gamification to increase their motivation was developed combining with Web-GIS and sightseeing planning and sharing system. Regarding the usefulness of the system, there are 4 points related to obtaining prior sightseeing information and real-time information as well as grasp of the locations sightseeing spots and continuous utilization of the system.

2) The operation target area of the system was Chofu City, Tokyo Metropolis. The system was operated over a 2-week period with people inside and outside Chofu City. The total number of system users was 51 with many in their 20s, and only $27 \%$ lived within Chofu City. There were 17 sightseeing plans created and 30 new sightseeing spots registered by the users during the operation period. Therefore, by operating the system for an extended period, it can be anticipated that there will be an increase in the creation of new sightseeing plans and the registration of new sightseeing spots.

3) A questionnaire survey and access log analysis for users were conducted in 
order to evaluate the system. According to the results of the questionnaire survey, though the operability of the 3 main functions incorporated with motivations by gamification was rated lower than the 2 basic functions, their usefulness was highly rated. Therefore, by the continuous utilization of the system, it can be anticipated that users will become familiarized with the operation of the main functions and be able to easily utilize them. The results of the access log analysis indicated that it was effective to design the system so that the same functions can be used regardless of the type of information terminal. Additionally, it was evident that the continuous utilization of the system could increase the number of sightseeing plans created by the users.

Additionally, the present study has the limitations concerning the issues of the system identified based on the results of the questionnaire survey and access log analysis and summarized in Section 6.3. Therefore, as future research subjects, firstly, it is necessary to improve the system according to the improvement plan identified in Section 6.3, which is related to web page designs, function of sightseeing plan creating and sharing, and Effective introduction of increasing motivation by gamification. Next, it is hopeful to operate the improved system in other urban areas in order to enhance the significance of utilization.

\section{Acknowledgements}

In the operation of the sightseeing planning support system with gamification and the web questionnaires survey of the present study, enormous cooperation was received from participants, mainly in the Tokyo Metropolitan Area. We wish to take this opportunity to gratefully acknowledge them.

\section{Conflicts of Interest}

The authors declare no conflicts of interest regarding the publication of this paper.

\section{References}

[1] Basten, D. (2017) Gamification. IEEE Software, 34, 76-81. https://doi.org/10.1109/MS.2017.3571581

[2] Stieglitz, S., Lattemann, C., Robra-Bissantz, S., Zarnekow, R. and Brockmann, T. (2017) Gamification: Using Game Elements in Serious Contexts. Springer, Berlin. https://doi.org/10.1007/978-3-319-45557-0

[3] Werbach, K. and Hunter, D. (2020) For the Win: The Power of Gamification and Game Thinking in Business, Education, Government, and Social Impact. Wharton School Press, Philadelphia.

[4] Kim, S., Song, K., Lockee, B. and Burton, J. (2018) Gamification Cases in Education: Enjoy Learning Like Gaming. Springer, Berlin. https://doi.org/10.1007/978-3-319-47283-6_10

[5] Dreimane, S. (2018) Gamification for Education: Review of Current Publications. In: Daniela, L., Ed., Didactics of Smart Pedagogy: Smart Pedagogy for Technology Enhanced Learning, Springer, Berlin, 453-464. https://doi.org/10.1007/978-3-030-01551-0_23 
[6] Turan, Z., Avinc, Z., Kara, K. and Goktas, Y. (2016) Gamification and Education: Achievements, Cognitive Loads, and Views of Students. International Journal of Emerging Technologies in Learning, 11, 64-69. https://doi.org/10.3991/ijet.v11i07.5455

[7] Van Roy, R. and Zaman, B. (2018) Need-Supporting Gamification in Education: An Assessment of Motivational Effects over Time. Computer \& Education, 127, 283-297. https://doi.org/10.1016/j.compedu.2018.08.018

[8] Ozcinar, Z., Zakirova, V. and Kurbanov, R. (2019) Analysis of the Documents Published in the Web of Science Database on Teachers' Gamification Method: A Content Analysis. International Journal of Emerging Technologies in Learning, 14, 82-94. https://doi.org/10.3991/ijet.v14i22.11741

[9] Yamakawa, S. and Hirosue, M. (2020) Development of the Environmental Awareness Board Game and Attempt of Participation Type Education for the Next-Generation. The Japanese Journal Persuasion and Negotiation, 12, 33-40.

[10] Aoe, M., Park, H.S., Yasuhara, S., Kushihata, T., Ueta, M., Nagata, M. and Ezaki, S. (2020) A Trial and Evaluation of Organic Chemistry Education Using Aamification for First-Year Pharmacy Students. Japanese journal of pharmaceutical education, 4, 147-156.

[11] Kurata, Y., Shinagawa, Y. and Hara, T. (2015) CT-Planner 5: A Computer-Aided Tour Planning Service Which Profits Both Tourists and Destinations. Proceedings of the Workshop on Tourism Recommender Systems, 15, 35-42.

[12] Brilhante, I.R., Macedo, J.A., Nardini, F.M., Perego, R. and Renso, C. (2015) On Planning Sightseeing Tours with TripBuilder. Information Processing \& Management, 51, 1-15. https://doi.org/10.1016/j.ipm.2014.10.003

[13] Cenamor, I., De La Rosa, T., Núñez, S. and Borrajo, D. (2017) Planning for Tourism Routes Using Social Networks. Expert Systems with Applications, 69, 1-9. https://doi.org/10.1016/j.eswa.2016.10.030

[14] Yamamoto, K. (2017) Navigation System for Foreign Tourists in Japan. Journal of Environmental Science and Engineering, 10, 521-541.

[15] Abe, S., Yoshitsugu, N., Miki, D. and Yamamoto, K. (2019) An Information Retrieval System with Language-Barrier-Free Interfaces. Journal of Information Systems Society of Japan, 14, 57-64.

[16] Ravi, L., Subramaniyaswamy, V., Vijayakumar, V., Chen, S., Karmel, A. and Devarajan, M. (2019) Hybrid Location-Based Recommender System for Mobility and Travel Planning. Mobile Networks and Applications, 24, 1226-1239. https://doi.org/10.1007/s11036-019-01260-4

[17] Ikizawa-Naitou, K. and Yamamoto, Y. (2020) A Support System of Sightseeing Tour Planning Using Public Transportation in Japanese Rural Areas. Journal of Civil Engineering and Architecture, 14, 316-332. https://doi.org/10.17265/1934-7359/2020.06.003

[18] Ravi, L. and Vairavasundaram, V. (2016) A Collaborative Location Based Travel Recommendation System through Enhanced Rating Prediction for the Group of Users. Computational Intelligence and Neuroscience, 2016, Article ID: 1291358. https://doi.org/10.1155/2016/1291358

[19] Chen, C., Chen, X., Wang, Z., Wang, Y. and Zhang, D. (2017) Scenic Planner: Planning Scenic Travel Routes Leveraging Heterogeneous User-Generated Digital Footprints. Frontiers of Computer, 11, 61-79. https://doi.org/10.1007/s11704-016-5550-2

[20] Yanagisawa, Y. and Yamamoto, K. (2012) A Study on Information Sharing GIS to 
Accumulate Local Knowledge in Local Communities. Theory and Applications of GIS, 20, 61-70. https://doi.org/10.5638/thagis.20.61

[21] Nakahara, H., Yanagisawa, Y. and Yamamoto, K. (2012) Study on a Web-GIS to Support the Communication of Regional Knowledge in Regional Communities: Focusing on Regional Residents' Experiential Knowledge. Socio-Informatics, 1, 77-92.

[22] Okazaki, R., Hirotomo, M., Mori, K. and Shiraishi, Y. (2013) Dual-Purpose Information Sharing System for Direct User Support in Both Ordinary and Emergency Times. IPSJ Journal, 55, 1778-1786.

[23] Usuda, Y., hanashima, M., Sato, R. and Sano, H. (2017) Effects and Issues of Information Sharing System for Disaster Response. Journal of Disaster Research, 12, 1002-1014. https://doi.org/10.20965/jdr.2017.p1002

[24] Okuma, T. and Yamamoto, K. (2013) Study on a Social Media GIS to Accumulate Urban Disaster Information: Accumulation of Disaster Information during Normal Times for Disaster Reduction Measures. Scio-Informatics, 2, 49-65.

[25] Murakoshi, T. and Yamamoto, K. (2014) Study on a Social Media GIS to Support the Utilization of Disaster Information: For Disaster Reduction Measures from Normal Times to Disaster Outbreak Times. Scio-Informatics, 3, 17-30.

[26] Platt, J.E., Jacobson, P.D. and Kardia, S.L.R. (2018) Public Trust in Health Information Sharing: A Measure of System Trust. Health Research Service, 53, 824-845. https://doi.org/10.1111/1475-6773.12654

[27] Kochan, C.G., Nowicki, D.R. and Sauser, B. (2018) Impact of Cloud-Based Information Sharing on Hospital Supply Chain Performance: A System Dynamics Framework. International Journal of Production Economics, 195, 168-185.

https://doi.org/10.1016/j.ijpe.2017.10.008

[28] Chen, C.L., Yang, T.T. and Deng, Y.Y. (2020) A Secure Internet of Things Medical Information Sharing and Emergency Notification System Based on Nonrepudiation Mechanism. Transaction on Emerging Telecommunications Technologies, 32, e3946. https://doi.org/10.1002/ett.3946

[29] Ishikawa, S., Izumi, R., Asakimori, H., Yamada, S., Kunieda, T., Kometani, Y., Gotoda, N. and Yaegashi, R. (2020) Supporting System for Visiting Sightseeing Spot Using Image Recognition and Processing Technology (KadaBingo). In: Virvou, M., Nakagawa, H. and Jain, L.C., Eds., Knowledge-Based Software Engineering. 2020, Springer, Berlin, 141-151. https://doi.org/10.1007/978-3-030-53949-8_13

[30] Kawanaka, S., Matsuda Y., Suwa, H., Fujimoto, M., Arakawa, Y. and Yasumoto, K. (2020) Gamified Participatory Sensing in Tourism: An Experimental Study of the Effects on Tourist Behavior and Satisfaction. Smart Cities, 3, 736-757. https://doi.org/10.3390/smartcities3030037

[31] Hidaka, M., Kanaya, Y., Kawanaka, S., Matsuda, Y., Nakamura, Y., Suwa, H., Fujimoto, M., Arakawa, Y. and Yasumoto, K. (2020) On-Site Trip Planning Support System Based on Dynamic Information on Tourism Spots. Smart Cities, 3, 212-231. https://doi.org/10.3390/smartcities3020013

[32] Egger, I., Lei, S.I. and Wassler, P. (2020) Digital Free Tourism-An Exploratory Study of Tourist Motivations. Tourism Management, 79, Article ID: 104098. https://doi.org/10.1016/j.tourman.2020.104098

[33] Mesáro, P., Mandičák, T., Hernandez, M.F. and Sido, C. (2016) Use of Augmented Reality and Gamification Techniques in Tourism. e-Review of Tourism Research, 13, 366-381.

[34] Bujari, A., Ciman, M., Gaggi, O. and Palazzi, C.E. (2017) Using Gamification to 
Discover Cultural Heritage Locations from Geo-Tagged Photos. Personal and Ubiquitous Computing, 21, 235-252. https://doi.org/10.1007/s00779-016-0989-6

[35] Panou, C., Ragia, L., Dimelli, D. and Mania, K. (2018) An Architecture for Mobile Outdoors Augmented Reality for Cultural Heritage. International Journal of GeoInformation, 7, 463. https://doi.org/10.3390/ijgi7120463

[36] Kotsopoulos, K.I., Chourdaki, P., Tsolis, D., Antoniadis, R., Pavlidis, G. and Assimakopoulos, N. (2019) An Authoring Platform for Developing Smart Apps Which Elevate Cultural Heritage Experiences: A System Dynamics Approach in Gamification. Journal of Ambient Intelligence and Humanized Computing, 10, 17 p. https://doi.org/10.1007/s12652-019-01505-w

[37] Kurata, Y. (2012) Prospect on Sightseeing Excursion Support Game. Proceedings of the 7 th Annual Meeting of the Society for Tourism Informatics, Osaka, 14 December $2012,8 \mathrm{p}$.

[38] 4travel.jp. https://4travel.jp 